\title{
Evaluation of a teacher-led physical activity curriculum to increase preschooler physical activity
} \author{
Janice Bunn ${ }^{4}$, Jean Harvey-Berino ${ }^{1}$ \\ ${ }^{1}$ Department of Nutrition and Food Sciences, University of Vermont, Burlington, USA; \\ ${ }^{*}$ Corresponding Author: efpope@uvm.edu \\ ${ }^{2}$ Vermont Child Health Improvement Program, University of Vermont, Burlington, USA \\ ${ }^{3}$ Office of Health Promotion Research, University of Vermont, Burlington, USA \\ ${ }^{4}$ Department University Mathematics \& Statistics, University of Vermont, Burlington, USA
}

Margaret Dunn-Carver ${ }^{1}$, Lizzy Pope ${ }^{1^{*}}$, Gregory Dana $^{2}$, Anne Dorwaldt $^{3}$, Brian Flynn ${ }^{3}$,

Received 12 January 2013; revised 12 February 2013; accepted 19 February 2013

\begin{abstract}
Preschool students are generally sedentary at school, and few interventions have addressed whether teacher-led activities can increase physical activity at preschools. The current study aimed to increase physical activity in preschool children enrolled in childcare centers by training childcare providers to deliver a physical activity curriculum. A within-group pre-test/post-test design was used including 32 children at 4 preschools. A teacher-led physical activity curriculum, the Coordinated Approach to Child Health Early Childhood Education Curriculum (CEC) was implemented in each childcare center for six weeks. Activity levels of participants were monitored through the use of accelerometers and direct observation for approximately five hours pre- and post-intervention. Time spent in moderate/vigorous physical activity in preschoolers in three of the four preschools suggested a positive trend increasing from $34.5 \% \pm 13.2 \%$ baseline to $39.3 \% \pm 15.4 \%$ at follow-up $(p=0.10)$. Teachers from all four centers reported spending $24.6 \pm 13.0$ minutes per activity session with up to two activity sessions completed per day. These results justify larger trials to determine the impact of a teacher-led physical activity curriculum on the intensity and duration of preschool students' physical activity at school.
\end{abstract}

Keywords: Component; Formatting; Style; Styling

\section{INTRODUCTION}

In $2007-200810.4 \%$ of 2 - 5 years olds were estimated to be obese and $10.8 \%$ overweight $[1,2]$. This trend sig- nifies a national shift toward positive energy balance even in young children [3]. Physical activity is an important contributor to energy balance, and several longitudinal studies have demonstrated that physical activity levels are related to weight status in children [4,5]. Additionally, adequate physical activity promotes other positive health outcomes including increased self-esteem, cognitive health, bone formation, overall fitness, and reduced cardiovascular risk factors [6-8]. Furthermore, physical activity behaviors formed during childhood likely persist into adulthood [9-11].

In $2007-2008,60 \%$ or 4.2 million children ages 3 - 5 attended preschools. These environments may play a pivotal role in helping children attain adequate physical activity levels $[12,13]$. Despite the perception that preschoolers are constantly moving during the preschool day, evidence suggests that children in this age group are not getting the recommended amounts of physical activity (PA). Recent studies have revealed that preschoolers typically spend a substantial amount of time (70\% - 90\% of their day) in sedentary behavior [14-17]. These findings suggest that the current level of PA that preschoolers engage in may not meet the recently published Institute of Medicine (IOM) preschool physical activity recommendations to prevent early childhood obesity, which suggest providing opportunities for light, moderate, and vigorous physical activity for at least 15 minutes per hour in childcare [18].

Studies have investigated the effectiveness of several physical activity promotion interventions for younger children. These studies employed approaches including increased recess time, health promotion programs, weight control programs, play equipment, and teacherguided physical activities in classrooms or on playgrounds [13,19-27]. Several of these studies found positive intervention effects including increased physical activity levels, higher mean heart rate, and more time 
spent in vigorous and moderate to vigorous physical activity (MVPA).

Key physical activity promotion targets include physical environment, center policies, staff training, and opportunities for increasing physical activity throughout preschool curricula [28]. Few studies have focused on the association between teacher-guided physical activity and the intensity, duration, and contextual aspects of physical activity [20,21]. Several cross-sectional studies have shown that staff training in physical education is positively associated with children's physical activity $[20,29]$. However, to our knowledge, intervention studies have not succeeded in showing a positive effect of a focused teacher training, and subsequent curriculum implementation on physical activity of preschool students $[28,30]$. This study sought to increase physical activity in preschool children enrolled in childcare centers by training childcare providers to deliver a widely available preschool physical activity curriculum. We hypothesized that a teacher-led, physical activity intervention would increase the time and intensity of preschool children's physical activity.

\section{METHODS}

\subsection{Participants}

The study was conducted within preschool classrooms at four licensed childcare centers in Vermont. Potential centers were selected with consideration of the number of children available in the targeted 4 - 5 years age group, the amount of space available to feasibly implement the intervention program activities, absence of a significant physical activity asset such as a gym at the facility, and diversity of the populations served. Enrollment of centers occurred from December 2009 to January 2010.

All children ages 4 - 5 attending the enrolled centers were eligible for the study. Center staff provided consent forms and letters describing the study and data collection procedures to parents of 4 - 5 year-old children. Centers were offered an incentive of $\$ 400$ for participation, in addition to staff training and equipment needed to implement the curriculum. Thirty-two children participated in the study.

\subsection{Instruments}

Measures used to document impact, implementation, and acceptability of the CEC program included objective measures of physical activity, observer reports, and logs and surveys provided by participating teachers.

Physical Activity Measurement. Children's physical activity was measured with a SenseWear ${ }^{\mathbb{B}}$ Pro 3 armband (BodyMedia, Pittsburgh, PA) (SWA) during the baseline and follow-up periods. SWA assessed physical activity levels over time as average metabolic equivalent of task
(MET) per minute. The device is worn on the triceps of the upper right arm and held in place by a Velcro armband strap. It uses a combination of five sensors, including a two-axis accelerometer, plus participant's height, weight, and age to calculate total energy expenditure, active energy expenditure, average MET levels, number of steps, and sleep and lying down duration for each minute of use. The SWA has been tested in a variety of adult populations and has been validated in resting state, during exercise, and in obese individuals [31]. Furthermore, recent studies by Calabro et al. showed that SWAs validly assess physical activity in children $[32,33]$. The output of interest for this study was physical activity by MET levels: sedentary ( $\leq 1.4$ METs), light (1.5 - 2.9), moderate ( $>3$ to $5.9 \mathrm{METs}$ ), and vigorous ( $\geq 6 \mathrm{METs})$ [34].

Direct Observation of Children's Activities. Trained study staff conducted direct observations recording a sequence of activity categories for individual children delimited by specific times that could be linked with minute-by-minute accelerometer measures of activity levels for the same children over these time periods. Observers recorded a brief description of each of the 4-5 children they were following on a structured form. Observers then recorded the time each new type of activity began throughout the observation period. Observers also indicated whether the activity was indoors or outdoors, and whether the activity was a teacher-guided activity or free-play activity. After the observation session, each activity was further categorized by additional codes indicating whether the activity was free play with a gross motor emphasis (FGM), teacher-led gross motor (TGM) play, or manipulative, sedentary, sedentary with limb movement, transitional, or unique activity. These categories were adapted from Brown et al [35]. A review by Pate et al. indicated that both direct observation systems and accelerometry are well established, valid, reliable, and complimentary measures of physical activity in young children [36].

Height and Weight. Anthropometric measures were taken on the first day of baseline measurements with children wearing street clothes and without shoes. Research staff used a calibrated floor scale (Tanita, BWB$800 \mathrm{~A}$ ) to measure weight; height was measured using a wall-mounted tape measure with square on head. Body Mass Index (BMI) was calculated as weight $(\mathrm{kg}) /$ height $\left(\mathrm{m}^{2}\right)$ and BMI-for-age percentile was calculated using standard growth charts [37].

Teacher Logs and Post-Intervention Surveys. Participating teachers completed daily logs of CEC lessons used and lesson duration during the 6-week curriculum implementation. They indicated how closely the activities were followed using a scale where $1=$ not at all and 4 = completely. Children's level of enthusiasm in re- 
sponse to the activities was recorded using a scale where $1=$ not at all enthusiastic and $5=$ extremely enthusiastic. Teachers also were asked to complete a semi-structured post-intervention survey regarding the acceptability and ease of implementation of the CEC curriculum.

Observer Reports. A physical education teacher and a research staff member visited participating classrooms 2 3 weeks into the intervention period to observe whether the CEC activities were being implemented as intended. Observations occurred for one half day in each center, and observer reports were filled out using a form adapted from CEC evaluation materials.

\subsection{Procedure}

This 10-week study used a pre-test/post-test design. Baseline measures were conducted in February/March 2010, a six-week intervention occurred, and follow-up measures were conducted in April/May 2010. In both the baseline and follow-up periods assessments of participating children's physical activity levels were completed over two consecutive mornings at the childcare center. Teachers attended a one-day training on the Coordinated Approach to Child Health (CATCH) elementary education program and then implemented the curriculum for six weeks, keeping logs of the components implemented.

The CATCH Early Childhood Curriculum (CEC) is based on the grades 3 - 5 Coordinated Approach to Child Health (CATCH) elementary education program [38]. The CATCH program uses Social Cognitive Theory as a foundation for the design of activities to promote positive changes in multiple health behaviors, including physical activity. Preliminary evaluations of the CEC program demonstrated feasibility and acceptability among children, teachers and parents [39]. This study focused on the CEC physical activity components aimed at increasing moderate to vigorous physical activity (MVPA) through classroom activities enhanced with play equipment, and stimulated by music and group games. Table 1 provides a description of activity categories and example activities.

Seven teachers from the four centers participated in a one-day CEC curriculum training conducted by a CATCH/ CEC National Training Staff member. Each center received the CEC physical education curriculum kit and accompanying equipment. Participating teachers were asked to implement at least two CEC curriculum activity sessions per day during the six-week intervention period ( $\sim 60$ minutes per day). There was no additional supervision during this period.

\subsection{Data Analysis}

Data from the SWAs were downloaded into individual
Table 1. CATCH early childhood activity categories.

\begin{tabular}{|c|c|}
\hline I. Warm-up & $\begin{array}{l}\text { Short } 3 \text { - } 5 \text { minutes activities designed to prepare } \\
\text { for more vigorous movement }\end{array}$ \\
\hline II. Go Fitness & $\begin{array}{l}\text { Intended to promote muscular strength, muscular } \\
\text { endurance, and cardiovascular endurance }\end{array}$ \\
\hline III. Go Activity & $\begin{array}{l}\text { Activities that develop fundamental motor skills } \\
\text { and rhythm }\end{array}$ \\
\hline IV. Limber Limbs & $\begin{array}{l}\text { Purposeful movement to improve muscular range } \\
\text { of motion such as stretching and twisting }\end{array}$ \\
\hline V. Cool Down & $\begin{array}{l}\text { Cool down students' bodies and help with } \\
\text { transition back to the classroom }\end{array}$ \\
\hline
\end{tabular}

files for each participant for each observation session. Data were analyzed using Inner View Research Software (version 6.1) provided by the SWA manufacturer. Observation data (e.g., indoor/outdoor, guided/free play) was hand coded and linked by time stamp to SWA data. Continuous variables are reported as means \pm standard deviations; categorical variables are reported as frequencies and percentages. The analytic approach was a single-group repeated measures analysis of variance. For analysis of baseline-to-follow up intervention changes, time point was considered a fixed effect, with random variables included to account for the correlation among repeated measures taken on the same child as well as the correlation among children clustered within a preschool program. These analyses included only those children with data collected in both time points. All analyses were performed using SAS, version 9.2 (SAS Institute Inc., 2002).

\section{RESULTS}

\subsection{Participant Descriptors}

Of 46 children with signed parental consent forms, 42 (91\%) participated in the study. Among these children, $32(76 \%)$ completed both baseline and follow-up measures. The mean age of participating children was $4.3 \pm$ 1.5 (range: 4 - 5) years; $46.3 \%$ were male. Participants had an average BMI of $15.9 \mathrm{~kg} / \mathrm{m}^{2} \pm 1.1 ; 2.4 \%$ were obese, and $12.2 \%$ were overweight. A completer versus non-completer analysis revealed no significant differences in age, gender, BMI, or baseline activity levels between children who completed all measures and those who did not. Therefore, analysis focused on children completing both baseline and follow-up measures $(\mathrm{n}=$ 32). Reasons why consented children did not complete the assessments included temporary absence and leaving the preschool program. Seven preschool teachers from the four centers participated in the CEC training, implemented the program in their classrooms, and completed a survey assessment of the curriculum at the end of the follow-up period. Five of these teachers logged the frequency, duration, and type of each CEC activity implemented. 


\subsection{Baseline Physical Activity Measurement}

Children in all four centers wore the SWA for an average of $332 \pm 91$ minutes at baseline (about 5.5 hours) over two mornings and $339 \pm 72$ minutes at follow-up (n $=32$ ). Among children participating in both assessments an average of $57 \% \pm 17 \%$ of time was sedentary at baseline. The average MET level per minute at baseline was $3.00 \pm 0.62$. The average MET levels for FGM was 3.76 $\pm 0.83(\mathrm{n}=31)$ and for TGM $4.21 \pm 1.03(\mathrm{n}=17)$.

\subsection{Physical Activity Level Changes at All Four Centers}

The percentage of time spent in MVPA MET levels among participating children $(\mathrm{n}=32)$ at baseline was $43.3 \% \pm 16.9 \%$ and at follow-up was $41.8 \% \pm 13.4 \%$ (p $=0.57)$ suggesting that there was no significant difference in time spent in MVPA before and after the intervention. However, examination of MET levels for each center at baseline and follow-up suggested that three of the centers may have experienced an increase in MET levels (Table 2).

Closer examination of center 3 data indicated that this center had relatively high physical activity levels at baseline and the intervention may have had no impact on overall physical activity intensity for these children. We observed that this program highly valued physical activity based on research staff interactions, teacher surveys, and the center's written mission. Therefore, center 3 was removed from further analyses to examine the effect of the intervention on preschool programs with a more typical management of physical activity.

\subsection{Physical Activity Level Changes for Centers 1, 2, and 4}

In the three remaining programs, 21 children participated at both baseline and follow-up assessments.

At baseline, these children spent $34.5 \% \pm 13.2 \%$ of their time in MVPA and at follow-up spent 39.3\% \pm $15.4 \%$ of their time in MVPA $(p=0.10)$. This difference suggests a trend toward increasing MET levels from baseline to follow-up among children in these classrooms. At baseline, these children spent an average of $30.6 \%$ of time sedentary, $34.9 \%$ in light activity and $31.8 \%$ in moderate activity; negligible amounts of time were spent in vigorous or very vigorous activity $(2.6 \%)$. Favorable changes in percent of time spent in various MET levels were noted at follow-up as shown in Figure 1, with a lesser proportion of time in sedentary behavior, and a greater proportion of time spent more active (sedentary decreased to $23.5 \%$, light increased to $37.2 \%$, moderate increased to $34.7 \%$, vigorous and very vigorous increased to $4.6 \%$ ). Further evaluation of activity types indicated that the average time spent in specific activity categories changed in these three centers between the two assessment points. Teacher-led gross motor (TGM) play increased by 44.0 minutes and sedentary time decreased by 27.1 minutes as shown in Figure 2.

Table 2. Percent of time spent in Moderate to Vigorous Physical Activity (MVPA) MET levels and time spent in MVPA per center for all children (42).

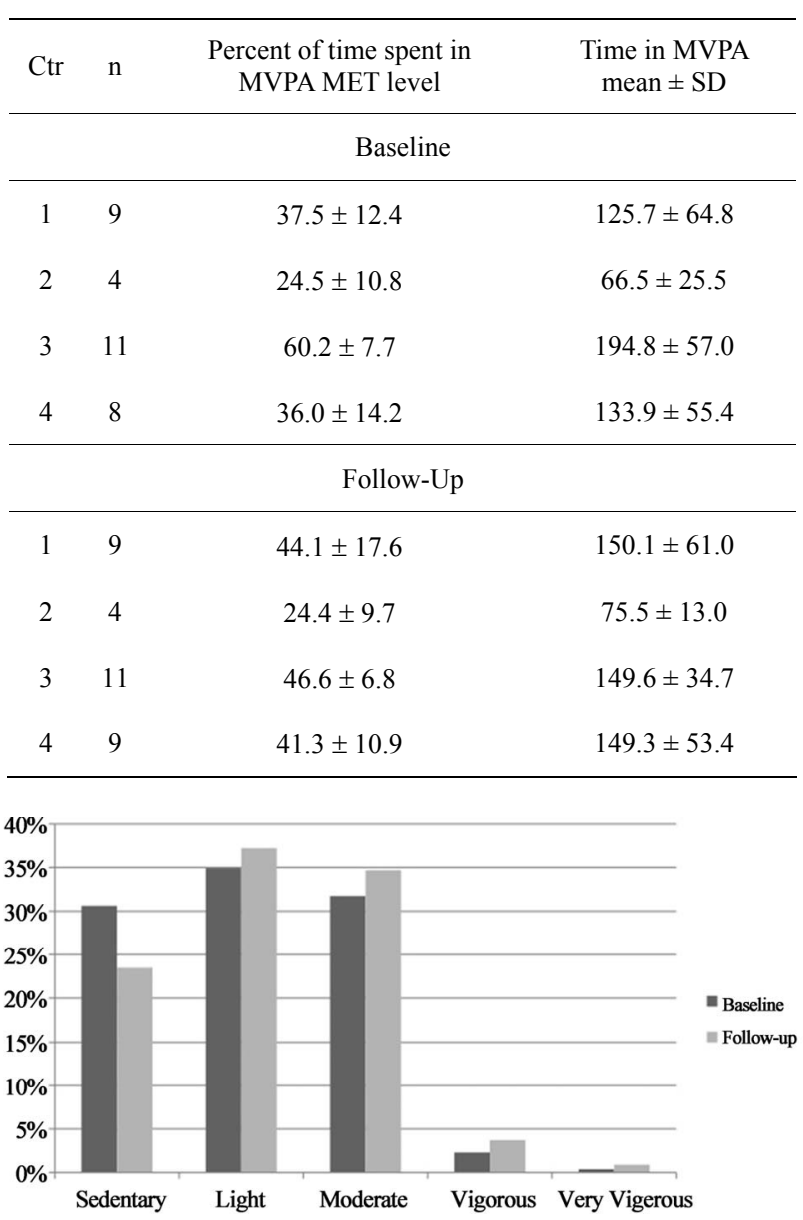

Figure 1. Percent of time spent in MET levels in three childcare centers at baseline and follow-up $(n=21)$.

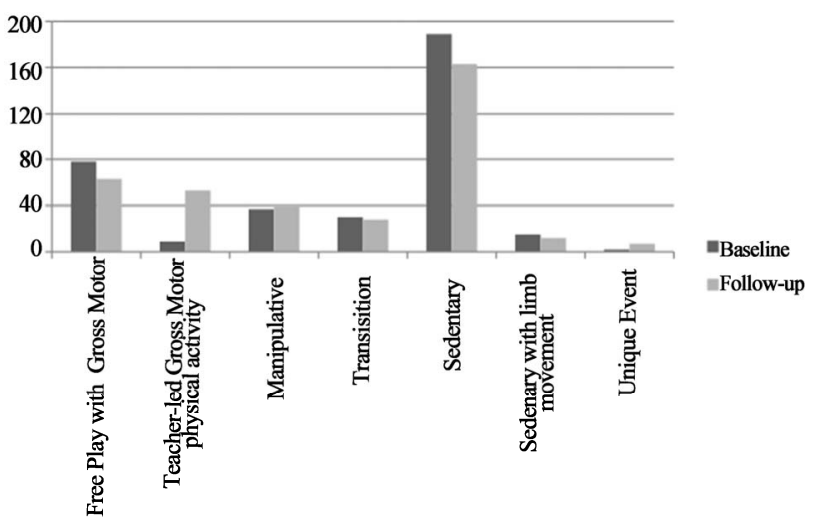

Figure 2. Average time in minutes spent in activity type at baseline and follow-up $(\mathrm{n}=21)$. 


\subsection{Teacher and Observer Reports}

Teachers from all four centers reported spending 24.6 \pm 13.0 minutes per CEC session with up to two sessions completed per day. Center 2 reported at least one CEC session over all 30 days; center 1 and 4 missed one day of CEC sessions; center 3 did not complete any sessions on 11 days. Teachers reported following the curriculum closely ( 3.15 where $1=$ not at all and $4=$ completely) and indicated that the children were generally enthusiastic $(3.94$ where $1=$ not enthusiastic and $5=$ very enthusiastic) about the program. Two independent observers also reported that children actively participated in the activities, which were conducted as designed.

\section{DISCUSSION}

The overall findings suggest that using a physical activity curriculum may be a feasible and effective approach to increasing physical activity among preschool students. During six weeks of implementing CEC, teachers logged at least 25 minutes of recommended activities per day and reported high levels of enthusiasm by the students. Independent observers reported high levels of participation by the children and the staff. In three childcare centers with lower baseline levels of physical activity, positive trends towards greater amounts of time in MVPA were observed. More specifically, child participation in teacher-led gross motor activities appeared to increase following implementation of the curriculum in these three centers, as intended by the CEC design. Assessments of children in one center that had higher baseline levels of MVPA did not reflect these positive trends, however.

On average during the baseline period, all four centers were sedentary or engaged in light activity for more than $50 \%$ of the observation time, and less than one percent of the time was spent in vigorous or very vigorous activity. When center three was removed from the analyses, we discovered that the centers spent on average almost $70 \%$ of the preschool day in sedentary or light behavior. In order to meet IOM guidelines recommending that children get at least 15 minutes of physical activity per hour, we requested that teachers incorporate at least two sessions of CEC per day. Unfortunately, most teachers did not meet this goal. This deficit may be explained by the challenge that teachers faced in engaging the children for the recommended structured physical activity time. Also, decreased ability to engage in active play may have resulted from space limitations in the childcare centers, an important environmental determinant of physical activity for children attending childcare $[13,20]$.

This study adds to the small amount of research focused on physical activity curriculum interventions for preschoolers. Use of multiple methods of evaluation to assess the context, duration, acceptability, feasibility, and intensity of physical activity during the school day is a strength of the study. This is the first study to use a multi-sensor armband accelerometer to quantify the impact of a physical activity curriculum on physical activity levels attained during the preschool day. The physical activity program was delivered by the usual preschool teaching staff rather than research staff or outside professionals, highlighting the potential of a one-day teacher training as a means to increase physical activity in preschool students.

\section{Limitations}

There were several limitations to this study. The study employed a within-group design, and therefore did not have a control group to account for the influence of secular or seasonal trends in activity. The sample size was small, limiting our ability to detect differences between baseline and follow-up measurements as statistically significant. Loss during follow up contributed to this limitation although it may be typical for this population. Another limitation was the short duration, as an average of five hours of observation per child over a limited time frame may not be sufficient to observe other factors that influence preschool physical activity. This study drew from a convenience sample population that may limit generalizability. Finally, although we did not collect ethnic or racial information, we are aware that overall the Vermont ethnic/race distribution is largely homogeneous which could also limit generalizability; it should be noted, however, that the CEC was developed in settings with more diverse populations.

\section{CONCLUSION}

Considering the detrimental health implications of a sedentary lifestyle for children and the rise in childhood obesity, activity at childcare centers remains a critical area of research. In fact, this area of research has been recognized as being increasingly important by the June 2011 IOM report suggesting that childcare regulatory agencies require that childcare providers engage preschool children in physical activity throughout the day [18]. The positive trends in MVPA among 4 - 5 years old at childcare centers found in this study suggest that a focused physical activity curriculum may be an effective way to increase activity during the preschool day. Additionally, preschool teachers reported a high level of satisfaction and efficacy in implementing the CEC program and perceived their students to be enthusiastic about the program. These results suggest that larger trials may be justified to provide stronger evidence for the impact of a CEC curriculum on the intensity and duration of preschool students' physical activity in childcare settings. 


\section{ACKNOWLEDGEMENTS}

The authors are grateful to the participating preschools, directors, providers, children and their parents who invested their time in the study. We would also like to acknowledge all members of the project team not listed as authors and Dr. David Brock for his valuable input. This work was supported by grant NIFA \#2008-04099 from the US Department of Agriculture awarded to Jean Harvey-Berino, R.D., Ph.D.

\section{REFERENCES}

[1] Ogden, C., Carroll, M., Curtin, L., Lamb, M. and Flegal, K. (2010) Prevalence of high body mass index in US children and adolescents, 2007-2008. Jama, 303, 242. doi:10.1001/jama.2009.2012

[2] Kim, J., Peterson, K., Scanlon, K., Fitzmaurice, G., Must, A., Oken, E., Rifas-Shiman, S., Rich-Edwards, J. and Gillman, M. (2006) Trends in Overweight from 1980 through 2001 among preschool-aged children enrolled in a Health Maintenance Organization. Obesity, 14, 1107-1112. doi:10.1038/oby.2006.126

[3] Troiano, R. and Flegal, K. (1998) Overweight children and adolescents: Description, epidemiology, and demographics. Pediatrics, 101, 497.

[4] Jago, R., Baranowski, T., Baranowski, J., Thompson, D., and Greaves, K. (2005) BMI from 3-6 y of age is predicted by TV viewing and physical activity, not diet. International Journal of Obesity, 29, 557-564. doi:10.1038/sj.ijo.0802969

[5] Moore, L., Gao, D., Bradlee, M., Cupples, L., Sundarajan-Ramamurti, A., Proctor, M., Hood, M., Singer, M. and Ellison, R. (2003) Does early physical activity predict body fat change throughout childhood? Preventive Medicine, 37, 10-17. doi:10.1016/S0091-7435(03)00048-3

[6] Fulton, J., Garg, M., Galuska, D., Rattay, K. and Caspersen C. (2004) Public health and clinical recommendations for physical activity and physical fitness: Special focus on overweight youth. Sports Medicine, 34, 581-599. doi:10.2165/00007256-200434090-00003

[7] Baranowski, T., Mendlein, J., Resnicow, K., Frank, E., Cullen, K.W. and Baranowski, J. (2000) Physical Activity and Nutrition in Children and Youth: An Overview of Obesity Prevention. Preventive Medicine, 31, S1-S10. doi:10.1006/pmed.2000.0686

[8] Hillman, C., Erickson, K. and Kramer. A. (2008) Be smart, exercise your heart: Exercise effects on brain and cognition. Nature Reviews Neuroscience, 9, 58-65. doi:10.1038/nrn2298

[9] Bandura, A. (2004) Health promotion by social cognitive means. Health Education \& Behavior, 31, 143. doi:10.1177/1090198104263660

[10] Birch, L. and Fisher, J. (1998) Development of eating behaviors among children and adolescents. Pediatrics, 101, 539.

[11] Telama, R., Yang, X., Viikari, J., Wanne, I.O. and Raitakari, O. (2005) Physical activity from childhood to adulthood: A 21-year tracking study. American Journal of Preventive Medicine, 28, 267-273. doi:10.1016/j.amepre.2004.12.003

[12] (2009) America's children: Key national indicators of well-being.

http://www.childstats.gov/americaschildren/famsoc3.asp

[13] Dowda, M., Brown, W., McIver, K., Pfeiffer, K., O’Neill, J., Addy, C. and Pate, R. (2009) Policies and characteristics of the preschool environment and physical activity of young children. Pediatrics, 123, e261. doi: 10.1542/peds.2008-2498

[14] Reilly, J. (2010) Low levels of objectively measured physical activity in preschoolers in childcare. Medicine \& Science in Sports \& Exercise, 42, 502-507. doi:10.1249/MSS.0b013e3181cea100

[15] Brown, W.H., Googe, H.S., McIver, K.L. and Rathel, J.M. (2009) Effects of teacher-encouraged physical activity on preschool playgrounds. Journal of Early Intervention, 31, 126-145. doi: $10.1177 / 1053815109331858$

[16] Pate, R., McIver, K., Dowda, M., Brown, W. and Addy, C. (2008) Directly observed physical activity levels in preschool children. Journal of School Health, 78, 438-444. doi:10.1111/j.1746-1561.2008.00327.x

[17] Reilly, J. (2008) Physical activity, sedentary behaviour and energy balance in the preschool child: Opportunities for early obesity prevention, Proceedings of the Nutrition Society, 67, 317-325. doi:10.1017/S0029665108008604

[18] Institute of Medicine of the National Acedmies (2011) Early childhood obesity prevention policies. Washington DC.

[19] Hannon, J. and Brown, B. (2008) Increasing preschoolers' physical activity intensities: An activity-friendly preschool playground intervention. Preventive Medicine, 46, 532-536. doi:10.1016/j.ypmed.2008.01.006

[20] Bower, J., Hales, D., Tate, D., Rubin, D., Benjamin, S. and Ward, D. (2008) The childcare environment and children's physical activity. American Journal of Preventive Medicine, 34, 23-29. doi:10.1016/j.amepre.2007.09.022

[21] Parish, L., Rudisill, M. and St Onge, P. (2007) Mastery motivational climate: Influence on physical play and heart rate in African American toddlers. Research Quarterly for Exercise \& Sport, 78, 171-178. doi:10.5641/193250307X13082490460823

[22] Alhassan, S., Sirard, J. and Robinson, T. (2007) The effects of increasing outdoor play time on physical activity in Latino preschool children. International Journal of Pediatric Obesity, 2, 153-158. doi:10.1080/17477160701520108

[23] Binkley, T. and Specker, B. (2004) Increased periosteal circumference remains present 12 months after an exercise intervention in preschool children. Bone, 35, 13831388. doi:10.1016/j.bone.2004.08.012

[24] Eliakim, A., Nemet, D., Balakirski, Y. and Epstein, Y. (2007) The effects of nutritional-physical activity schoolbased intervention on fatness and fitness in preschool children. Journal of Pediatric Endocrinology \& Metabolism, 20, 711-718.

[25] Fitzgibbon, M., Stolley, M., Schiffer, L., Van Horn, L., Kaufer, C.K. and Dyer, A. (2005) Two-year follow-up results for hip-hop to health Jr.: A randomized controlled 
trial for overweight prevention in preschool minority children. The Journal of pediatrics, 146, 618-625. doi:10.1016/i.jpeds.2004.12.019

[26] Reilly, J., Kelly, L., Montgomery, C., Williamson, A., Fisher, A. McColl, J., Lo Conte, R., Paton J. and Grant, S. (2006) Physical activity to prevent obesity in young children: Cluster randomized controlled trial. British Medical Journal, 333, 1041. doi:10.1136/bmj.38979.623773.55

[27] Trost, S., Fees, B. and Dzewaltowski, D. (2008) Feasibility and efficacy of a "move and learn" physical activity curriculum in preschool children. Journal of Physical Activity \& Health, 5, 88.

[28] Ward, D., Vaughn, A., McWilliams, C. and Hales, D. (2009) Physical activity at child care settings: Review and Research recommendations. American Journal of Lifestyle Medicine, 3, 474. doi:10.1177/1559827609341964

[29] Dowda, M., Pate, R., Trost, S., Almeida, M. and Sirard, J. (2004) Influences of preschool policies and practices on children's physical activity. Journal of Community Health, 29, 183-196. doi:10.1023/B:JOHE.0000022025.77294.af

[30] Reilly, J. and McDowell, Z. (2003) Physical activity interventions in the prevention and treatment of paediatric obesity: Systematic review and critical appraisal. Proceedings of the Nutrition Society, 62, 611-619. doi:10.1079/PNS2003276

[31] Papazoglou, D., Augello, G., Tagliaferri, M., Savia, G., Marzullo, P., Maltezos, E. and Liuzzi, A. (2006) Evaluation of a multisensor armband in estimating energy expenditure in obese individuals. Obesity, 14, 2217-2223. doi:10.1038/oby.2006.260

[32] Calabro, M., Welk, G. and Eisenmann, J. (2009) Validation of the sensewear pro armband algorithms in children. Medicine and Science in Sports and Exercise, 41, 1714. doi:10.1249/01.MSS.0000355193.19476.d5
[33] Calabro, M.A., Lee, J., De St-Maorice, P. and Welk, G.J. (2011) Validation of pattern-recognition monitors in children using doubly-labeled water. in American College of Sports Medicine Conference, 43, 132. doi:10.1249/01.MSS.0000403068.22614.ab

[34] Pate, R., Pfeiffer, K., Trost, S., Ziegler, P. and Dowda, M. (2004) Physical activity among children attending preschools. Pediatrics, 114, 1258-1263. doi:10.1542/peds.2003-1088-L

[35] Brown, W., Pfeiffer, K., Mclever, K., Dowda, M., Almeida, M. and Pate, R. (2006) Assessing preschool children's physical activity: The observational system for recording physical activity in children-preschool version. Research Quarterly for Exercise and Sport, 77, 167-176. doi:10.5641/027013606X13080769704361

[36] Pate, R., O’Neill, J. and Mitchell, J. (2010) Measurement of physical activity in preschool children. Medicine \& Science in Sports \& Exercise, 42, 508-512. doi:10.1249/MSS.0b013e3181cea116

[37] Kuczmarski, R., Ogden, C., Grummer-Strawn, L., Flegal, K., Guo, S., Wei, R., Mei, Z., Curtin, L., Roche, A. and Johnson, C. (2000) CDC growth charts: United States. Advance Data, 314, 1-27.

[38] Stone, E., McKenzie, T., Welk, G. and Booth, M. (1998) Effects of physical activity interventions in youth. American Journal of Preventive Medicine, 15, 298-315. doi:10.1016/S0749-3797(98)00082-8

[39] Sharma, S., Chuang, R.J. and Hedberg, A.M. (2011) Pilot testing CATCH early childhood: A preschool-based program aimed at promoting healthy nutrition and physical activity among 3 to 5 year old children enrolled in head start. American Journal of Health Education, 42, 12-23. doi:10.1080/19325037.2011.10599169 